\title{
Title-Orthodontic Correction of Class II Division 2 Malocclusion in an adult With Single Missing Incisor: Case Report
}

\author{
Sarah Asif*, Sandhya Maheshwari and Saba Khan \\ Department of Orthodontics and Dentofacial Orthopedics, Dr ZA Dental College, India
}

Submission: December 03, 2018; Published: January 08, 2019

*Corresponding author: Dr. Sarah Asif, Senior Resident, Department of Orthodontics and Dentofacial Orthopedics, Dr Ziauddin Ahmad Dental College, Aligarh Muslim University, Aligarh, Uttar Pradesh, India

Abstract

This case report describes the treatment of an adult with a skeletal Class II Division 2 malocclusion with coverbite. The patient also had an extracted lower central incisor resulting in the loss of anterior incisal guidance and a collapsed lower anterior region. The correction of the skeletal class II discrepancy was achieved by correction of the inclination of the maxillary incisors, opening of the bite and forward posturing of the mandible. The space in the lower anterior region was regained for replacement of the extracted incisor using a conventional Maryland bridge thereby establishing an anterior incisal guidance. Improvement in the smile and facial esthetics were achieved.

Keywords: Class II Division 2; Incisal Guidance; Coverbite; Missing Single Incisor

\section{Introduction}

In 1899 Angle [1-7] described about a lesser common variant of Class II malocclusion as being characterized by distal occlusion of the teeth in both lateral halves of the lower arch along with retrusion of upper incisors instead of their protrusion. With a prevalence rate of $2.4 \%$, class II division 2 malocclusion is recognized as a triad of signs- deep bite, retroclined maxillary incisors and posteriorly positioned mandibular dental arch or the mandibular jaw [1].

Later even a more severe pattern of class II division 2 was recognized by dentists in Germany termed as Deckbiss or the Coverbite. Coverbite is simply recognized as a condition where the mandibular incisors are completely covered by excessive overbite and retroclination of the maxillary incisors [2].

The class II division 2 pattern is also believed to have a strong genetic influence. Deep anterior overbite is seen to develop during the mixed dentition period. The expression of this phenomenon is usually seen when the maxillary incisors erupt at the age of 7-8years. This expression is more pronounced in an individual with a forward rotation of the mandible where the center of rotation lies in the condyle thereby resulting in the underdevelopment of lower anterior facial height. Although the growth in these individuals is restrained in the anterior region, due to the deep anterior overbite, the mandibular basal region specifically the chin and symphysial region continue to grow under independent genetic control $[3,5]$.

\section{Case Report}

A 22 year old girl reported to the department of orthodontics with the chief complaint of an impinging bite, non-pleasing smile and an extracted lower central incisor. As reported by the patient her mother also had a similar malocclusion justifying the inheritance pattern of the malocclusion. On extra oral examination the patient had a symmetrical face with a convex profile, competent lips and a strong chin. The upper lip protruded slightly against the lower lip. Both the maxillary and mandibular arches were of the square type. Smile analysis showed a normal smile line with a non-consonant smile arc and a Morley's ratio of $100 \%$. Intraoral examination revealed Angle's class II molar relationship bilaterally. A complete overbite with retroclined upper incisors including the canines was seen along with the upper incisal edges resting on the lower anterior gingival margins and causing trauma. The lower central incisor had been extracted at an age of 12 years resulting in loss of incisal guidance and collapsed lower incisors.

\section{Diagnosis and treatment objectives}

The patient was diagnosed as Angle's Class II division 2 malocclusion with a complete coverbite, End On Molar relationship on right side and Class II Molar relationship on left side, Class II Canine relationship on left side and Class I on right side, on a Skeletal Class II base with hypodivergent growth pattern and CVMI-VI. The main treatment objective was to correct the overjet, overbite and provide an incisal guidance to the patient by 


\section{Advances in Dentistry \& Oral Health}

replacing the lower incisor. Hence, a non-extraction treatment plan for correction the position of upper incisors, deep bite, midline shift, class II relation and replacement of the extracted incisor to achieve ideal incisal guidance was outlined (Figures 1 \& 2).

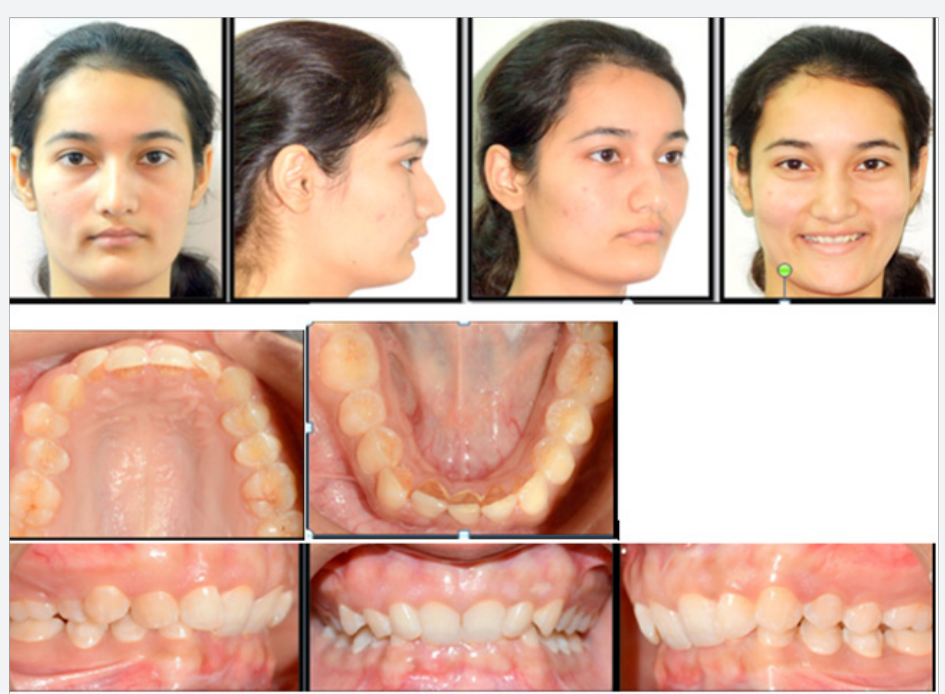

Figure 1: Pre-treatment extra oral and intra oral photographs.
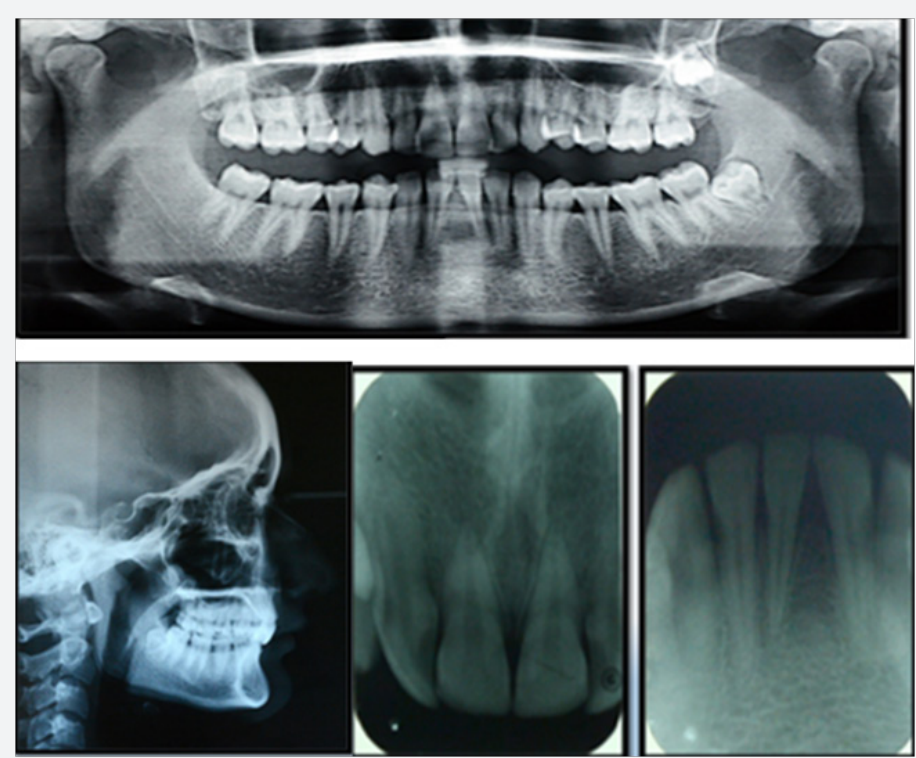

Figure 2: Pretreatment radiographs.

\section{Treatment Alternatives}

The main objective of the treatment was correction of the overjet and overbite and replacement of the missing central incisor. The best available treatment option for replacement of the missing central incisor was an implant prosthesis, which also involved a surgical intervention. Though the benefits of this treatment option were understood by the patient, the patient and her family were reluctant to opt for this option due to the surgical procedures involved and high cost of dental implants in addition to the expenses of orthodontic treatment. Hence, it was decided to proceed with the orthodontic correction of the malocclusion along with a resin bonded fixed partial denture.

\section{Treatment Progress}

The maxillary arch was banded and bonded using preadjusted edgewise appliance (MBT 0.022x0.028 slot) and an initial 0.016" NiTi wire was placed for leveling and alignment of the upper arch and correction of the inclination of the upper incisors. After significant correction in the inclination of the upper incisors and bite opening, the lower arch was banded and bonded and a continuous 0.016 " NiTi wire placed. Upon progression to round stainless steel wire, NiTi open coil spring was placed with respect to the missing lower right central incisor for regaining of space. Upper and lower wires were progressed up to $0.019 \times 0.025$ " stainless steel with incorporation of torque in the upper anterior 


\section{Advances in Dentistry \& Oral Health}

segment of the wire, to further correct the inclination of the incisors and canine. After optimum space was created for the lower central incisor a removable space maintainer was fabricated to maintain the space of the missing incisor until its replacement and completion of the active orthodontic treatment. Class II elastics were used for the correction of class II relationship (Figure 3).

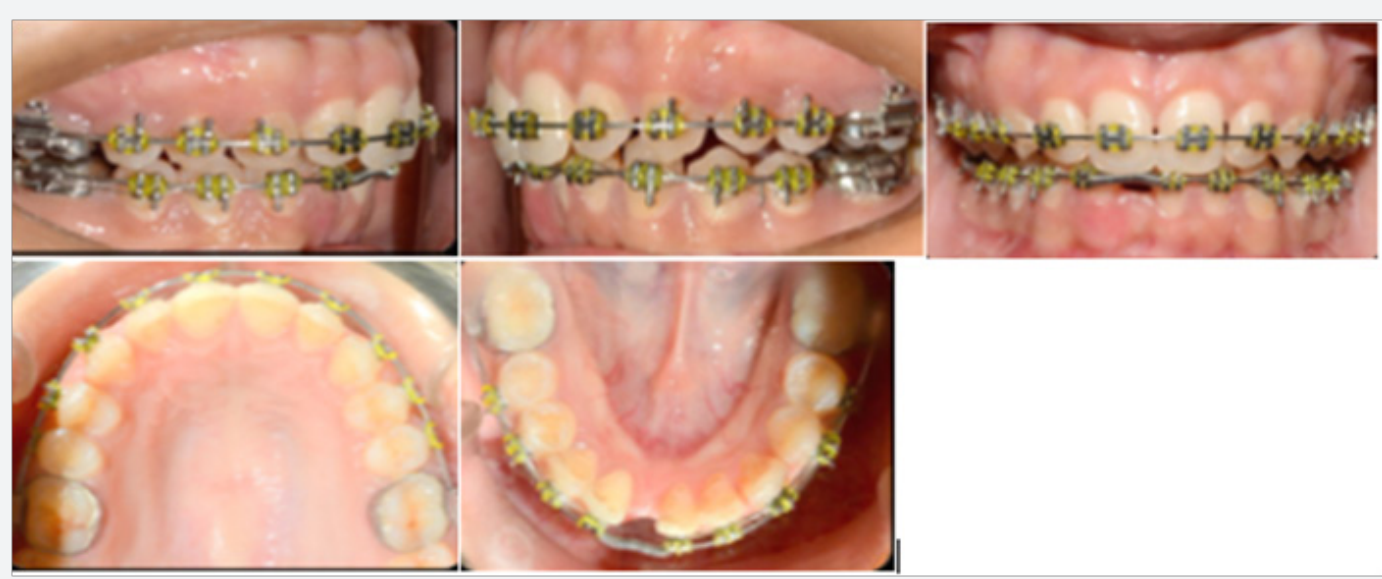

Figure 3: NiTi coil spring placed for space creation of missing 41 .

\section{Replacement of Lower Missing Incisor}

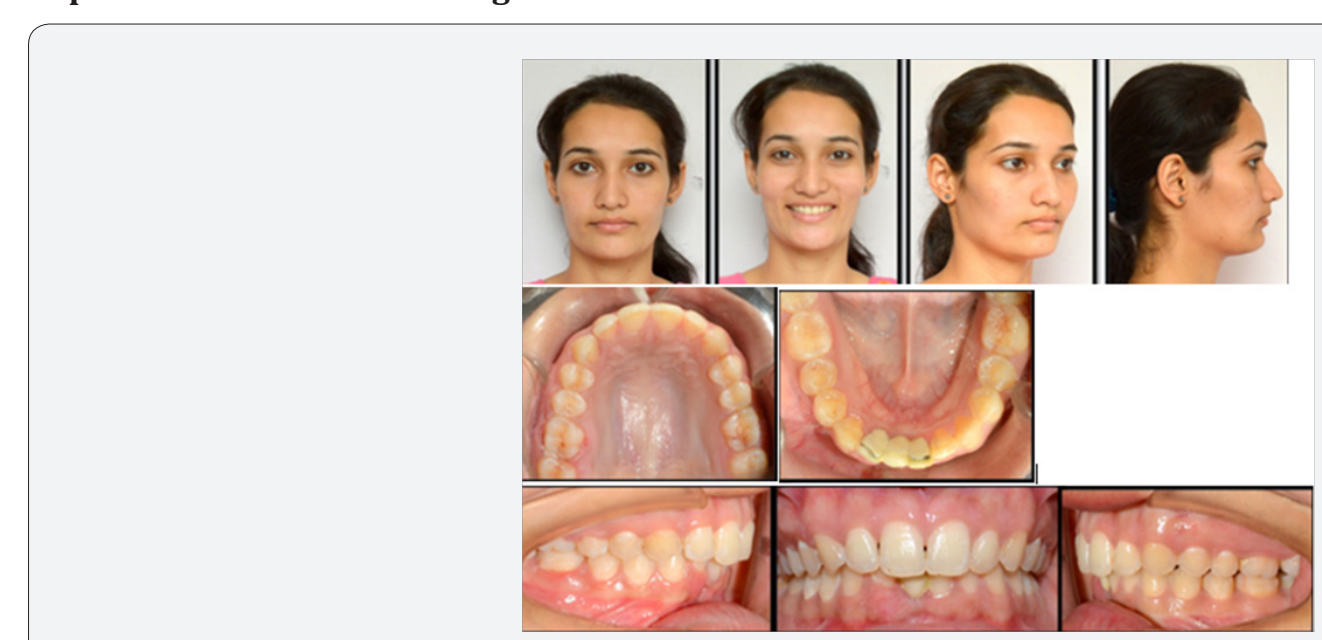

Figure 4: Post treatment extra oral photographs.

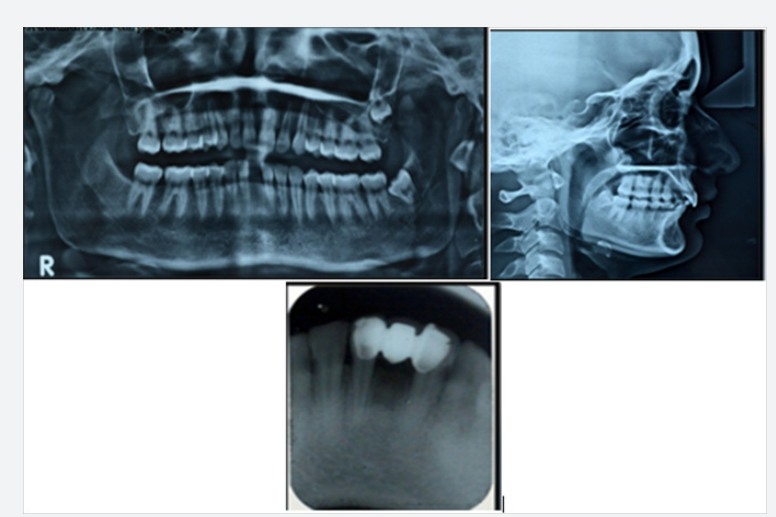

Figure 5: Post treatment photographs.

This aspect of the treatment required interdisciplinary management in collaboration with a prosthodontist. Since the patient undergoing the orthodontic treatment was an adult, the growth of the alveolar ridges had ceased and hence the post orthodontic restorative alternatives considered were; implant supported prosthesis or a fixed prosthesis such as resin bonded 
fixed partial denture or the Maryland bridge. Upon evaluation and assessment of the available alveolar bone width and depth the Maryland bridge was the most suitable prosthesis for the patient. Upon completion of the orthodontic treatment the appliance was de-bonded and upper removable retainer with anterior reverse incline plane to hold the mandible was given and a lower hawley's retainer was given. Also, a prosthetic replacement given in place of the missing lower incisor until the placement of the definitive prosthesis (Figures $4 \& 5$ ) (Table 1 ).

Table 1: Cephalometric table.

\begin{tabular}{|c|c|c|}
\hline Parameter & Pre-treatment & Post-treatment \\
\hline SNA & $81^{\circ}$ & $81^{\circ}$ \\
\hline SNB & $77^{\circ}$ & $77.5^{\circ}$ \\
\hline ANB $\left(3.12 \pm 1.8^{\circ}\right)$ & $4^{\circ}$ & $3.5^{\circ}$ \\
\hline N $\perp$ to A point $(-4.46 \mathrm{~mm})$ & $-4 \mathrm{~mm}$ & $-3 \mathrm{~mm}$ \\
\hline N $\perp$ to B point $(-11.03 \mathrm{~mm})$ & $-14 \mathrm{~mm}$ & $-11 \mathrm{~mm}$ \\
\hline N to Pog & $-12 \mathrm{~mm}$ & $-11 \mathrm{~mm}$ \\
\hline FMA $\left(28.83 \pm 2^{\circ}\right)$ & $21^{\circ}$ & $21^{\circ}$ \\
\hline SN-MP $\left(32-35^{\circ}\right)$ & $28^{\circ}$ & $4 \mathrm{~mm}$ \\
\hline Mx1 to NA $(4.92 \pm .05 \mathrm{~mm})$ & $4 \mathrm{~mm}$ & $20^{\circ}$ \\
\hline Mx1 to NA $\left(24.02 \pm 5.82^{\circ}\right)$ & $16^{\circ}$ & $6 \mathrm{~mm}^{\circ}$ \\
\hline Md1 to NB $(6 \pm 1.7 \mathrm{~mm})$ & $4 \mathrm{~mm}$ & $30^{\circ}$ \\
\hline Md1 to NB $\left(27 \pm 4.3^{\circ}\right)$ & $19^{\circ}$ & $109^{\circ}$ \\
\hline IMPA & $93^{\circ}$ & $-4 \mathrm{~mm}$ \\
\hline E-line Upper lip $(-4 \mathrm{~mm})$ & $-6 \mathrm{~mm}$ & $-2 \mathrm{~mm}$ \\
\hline E-line Lower lip $(-2 \mathrm{~mm})$ & $-3 \mathrm{~mm}$ & $96^{\circ}$ \\
\hline Nasolabial angle $\left(102^{\circ} \pm 4^{\circ}\right)$ & & \\
\hline
\end{tabular}

\section{Discussion}

Deep bite is one of the most common malocclusions and it is also said to be one of the most difficult to treat. Nanda2 stated that even a range of $25-40 \%$ in the absence of any associated functional or TMJ problem is normal. The etiology of deep bite can be a skeletal or a dental discrepancy and often deep bite is approached as a clinical manifestation of an underlying discrepancy. A skeletal deep bite is seen to be associated with a forward or a horizontal growth pattern wherein there is a growth discrepancy of the maxillary and mandibular jaw bases, convergent rotation of the jaw bones or a deficient mandibular ramus height. Whereas a dental deep bite results due to supraocclusion of incisors or under eruption of the molars or combination of both. In this patient, the deep bite was skeletal with the mandible positioned backward and a normal mandibular ramal length $[2,4]$.

Upon correction of the inclination of the upper incisors unlocking of the mandible was seen, allowing the posteriorly displaced mandible to move forwards thus simplifying the correction of the Class II discrepancy. This unlocking of the mandible was also seen in our patient which thereby negated the need of any additional class II force for forward reposition of the mandible. Also, since the ideal overjet was attained, there was no scope of any further advancement of the mandible. The use of class II elastics aided in retaining the forward position of the mandible along with a vertical component on the molars leading to the opening of bite further $[6,7]$.

Five important occlusal treatment goals depend on the correct contour and position of the lower anteriors; Esthetics, Phonetics, Occlusal plane, Anterior guidance and Stability. One of the principle roles of anterior guidance is also to protect the posterior occlusion by dis-occluding the posterior teeth during all the excursive movements. The lower incisal edges are also considered as the starting point for anterior guidance hence rendering them an important determinant in the post treatment stability of orthodontic treatment [8].

One of the main objectives of our treatment was replacement of the missing central incisor to establish a proper overjet, overbite and incisal guidance. Although, with the emerging trends an implant is the best prosthesis, however in this patient since the patient had to get the central incisor extracted at an early age, there wasn't adequate bone support in the region to receive an implant as prosthesis and therefore the Maryland bridge was preferred as the most suitable prosthesis. One of the advantages of the Maryland bridge is that it requires minimal preparation of the adjacent teeth surfaces since it is cemented directly onto the enamel of the teeth and poses minimal risk of sensitivity in the teeth post procedure.

\section{Conclusion}

Treating adults with Class II division 2 malocclusion is always challenging. However proper diagnosis of the underlying discrepancy and meticulous treatment planning aimed at the correction of the etiology is the surest way to achieve predictable results with minimal side effects. The proposed treatment goals helped us achieve a stable occlusion along with enhanced esthetics. The treatment provided to this patient produced a significantly enhanced occlusion, along with favorable profile and smile changes.

\section{References}

1. Cleall JF, BeGole EA (1982) Diagnosis and treatment of Class II division 2 malocclusion. Angle Orthod 52(1):38-60.

2. Nanda R Biomechanics and Esthetic Strategies in Clinical Orthodontics. R Nanda (Ed.), in press, WB Saunders Co, Philadelphia, USA.

3. Blair ES (1954) A cephalometric roentgenographic appraisal of the skeletal morphology of Class I, Class II division 1, and Class II division 2 malocclusions. Angle Orthod 24: 106-119.

4. Godiawala RN, Joshi MR (1974) A cephalometric comparison between Class II division 2 malocclusion and normal occlusion. Angle Orthod 44(3): 262-267.

5. Peck S, Peck L, Kataja M (1998) Class II division 2 malocclusion: a heritable pattern of small teeth in well-developed jaws. Angle Orthod 68(1): 9-20.

6. Trimmons LS (1972) Induced change in the anteroposterior relationship of the jaws. Angle Orthod 42(3): 245-250. 
7. Demisch A, Ingervall B, ThÜer U (1992) Mandibular displacement in Angle Class II, Division 2 malocclusion. Am J Orthod Dentofacial Orthop 102(6): 509-518.

This work is licensed under Creative Commons Attribution 4.0 License

DOI: 10.19080/ADOH.2019.10.555784
8. Dawson Peter E (1907) Functional Occlusion: From TMJ to Smile Design, $1^{\text {st }}$ edn., Elsevier Angle EH: Treatment of Malocclusion of the Teeth, $7^{\text {th }}$ edn. Philadelphia, USA.

\section{Your next submission with Juniper Publishers will reach you the below assets}

- Quality Editorial service

- Swift Peer Review

- Reprints availability

- E-prints Service

- Manuscript Podcast for convenient understanding

- Global attainment for your research

- Manuscript accessibility in different formats

( Pdf, E-pub, Full Text, Audio)

- Unceasing customer service

Track the below URL for one-step submission https://juniperpublishers.com/online-submission.php 